\title{
A neuropsychological instrument adding to the description of patients with suspected cortical dementia: the Milan overall dementia assessment
}

\author{
M Brazzelli, E Capitani, S Della Sala, H Spinnler, M Zuffi
}

\begin{abstract}
A new, short, neuropsychologically oriented test for dementia assessment-the Milan Overall Dementia Assessment (MODA)-is described.

Age and education adjusted norms based on 217 healthy controls are given. A validation study on 312 outpatients suspected of dementia (121 with probable Alzheimer's disease) showed that the MODA differentiated patients with cognitive impairment from normal subjects more effectively than did the DSM III-R.

The correlation between the MODA and the mini mental state examination was 0.63 in controls and 0.84 in patients with Alzheimer's dementia. The MODA test-retest reliability was $0 \cdot 83$. The test proved to be well suited to longitudinal studies.
\end{abstract}

(F Neurol Neurosurg Psychiatry 1994;57:1510-1517)

It is generally accepted that coping defects can arise from a number of neurological, psychiatric, and metabolic diseases. ${ }^{1}$ When these defects take a chronic progressive course, they are subsumed under the term of "dementia". In the diagnostic flow chart of patients with suspected dementia it is useful to include a step to verify the suspicion followed by one to establish its nosology. ${ }^{2-4}$

This study focuses on the steps necessary to confirm and stage dementia. Because no in vivo biological markers of either dementia or its nosology are currently available, verification of the presence of dementia has to be neurobehavioural. A widely accepted, all embracing conceptual framework of the psychological breakdown of dementia remains to be achieved, however. Therefore, the many approaches to the diagnosis of dementia are based on standardised descriptions of coping failures. These descriptions take the form of enquiries or test batteries.

Behavioural and neuropsychological investigations of patients with dementia yield data pertinent to the description and severity rating of the disease. It is worth specifying the main features of these classes of instruments so as to clearly establish those of the instrument presented in this paper.

BEDSIDE STANDARDISED INTERVIEWS

These are composed of heterogeneous items. The way in which they are assembled much depends on the cultural background of the examiner (geriatric, psychiatric, neurological), and the particular use for which they are intended (diagnostic, rehabilitative, experimental). There is often an array of items, exploring different topics, ranging from forgetfulness to psychotic traits, misperceptions to confusion, breakdown of social rules to communication disorders, alterations in eating and drinking habits to dizziness. The conclusion that the patient is already in the throes of a dementing process is reached by comparing the present state with the presumptive patient's premorbid state. The interview format is continuously updated at consensus conferences ${ }^{5}$ with the aim of adding items believed relevant to the final decision and removing those considered redundant. Bedside interviews yield semiquantitative measures, which are essentially a summation of checkmarks. ${ }^{6}$ Their main advantage is that they can be used to investigate patients affected by dementia due to different causes (for example, degenerative, metabolic, psychiatric); however, even the most acclaimed of these guided interviews (for example, DSMIII-R) ${ }^{7}$ is not substantially more informative than a carefully taken history.

\section{NEUROPSYCHOLOGICAL SCREENING}

\section{INSTRUMENTS}

Within this frame of reference, the symptoms of dementia are purported to be of a neuropsychological nature. ${ }^{8}$ Dementia is therefore conceived as an aggregation of deficits in several cognitive domains. The progressive increase in the number of these deficits contributes substantially to the ecological severity of dementia. It follows that diagnostic instruments are test batteries ${ }^{9}{ }^{10}$ structured along the traditional psychological taxonomy. ${ }^{311}$ As such, they are psychometrically sound, because patients' performances can be formally compared with norms adjusted for the influence of pathology independent variables such as age and education. Given the similarities between cognitive impairments due to focal damage and cortical dementia, this approach is based on the longstanding corpus of neuropsychological knowledge. Accordingly, batteries include tests to assess retrograde and anterograde memory processing, language, perceptual and spatial coping, and executive functions. Poor performances of demented patients are regarded as the result of different cognitive breakdowns due to encroachment of the degenerative process on 
specific cortical areas. Therefore, their use is presently restricted to cortical dementias, the model of which is Alzheimer's disease. A neuropsychologically oriented tool to ascertain "subcortical dementias" is still lacking.

Several neuropsychological instruments have been developed to assess cortical dementia, ranging from analytical batteries to brief screening instruments. ${ }^{2}$ The analytical approach provides insight into patients' spared and impaired cognitive abilities. ${ }^{3910}$ It is useful for research purposes or when it is necessary to demonstrate a specific cognitive pattern to confirm the diagnosis of a particular neuropsychological syndrome (for example, the so called focal degenerative cortical impairments). The analytical approach is, however, hampered by difficulties related to its administration ${ }^{12}$ rendering it unsuitable in severely deteriorated patients. ${ }^{13} 14$

Brief screening instruments, on the other hand, generally comprise a number of items that are summed up in a global score. They can be easily given, scored, and analysed, without extensive prior training. Furthermore, they are suitable for large epidemiological studies. ${ }^{15}$ The inclusion of very easy items widens the metric window whereby even severely deteriorated patients may be assessed.

The aim of this study was to present a new, neuropsychologically oriented instrument: The Milan Overall Dementia Assessment (MODA). It is a rapid rating scale generating a global score. The statistical procedure employed allows the clinician to detect the presence of an Alzheimer-like cognitive decline and measure the severity of the condition, although it provides no clues as to the nosology.

The paper is divided into two parts. Part 1 focuses on the norms of the MODA and the analysis of potentially influential variables such as age, education, and sex. Part 2 is a validation study in which the MODA and the DSM III-R supported clinical diagnoses are compared in a group of outpatients referred for suspected dementia.

\section{Part 1: normative study}

\section{Materials and methods}

EXPERIMENTAL SUBJECTS

Norms were provided by a sample of 217 healthy controls, 114 women and 103 men, varying widely in age and education. These volunteers were not paid to take part in the experiment. We aimed at collecting data from an even number of subjects for each of the demographic classes considered. They were recruited in six different districts in the north of Italy. Eighty per cent of the sample was recruited in rural or suburban areas, and the remaining $20 \%$ resided in city centres. Fifteen per cent of these subjects were recruited among healthy elderly people living in residential homes.

The mean age of the whole sample was 60.8 (SD 18.5, range 20-97) and their mean education was $9 \cdot 1$ (SD $4 \cdot 9$, range $1-17$ ) years. Criteria for inclusion were minimal literacy and neurological and mental health. Also, every patient had to have a reliable "witness". Table 1 shows the demographic variables of the group.

\section{TESTING PROCEDURES}

Milan Overall Dementia Assessment (MODA)

The MODA $^{1}$ is a paper and pencil test composed of three sections: a behavioural scale and two testing sections. The three sections are given in the same testing session in the same sequence. They are detailed in the appendix. (The Italian version of the MODA is distributed by the Organizzazioni Speciali, Via Scipione Ammirato, 37, Firenze, Italy.)

The behavioural component (autonomy scale) accounts for $15 \%$ of the score and comprises a set of items that aim to assess everyday coping skills. Information is provided by a relative and can therefore be collected even in cases of severe deterioration. The cognitive contribution in the MODA represents $85 \%$ of the score (orientation enquiry and neuropsychological testing yielding respectively 35\% and $50 \%$ of the overall score).

Scoring procedures-MODA total score ranges from a worst of 0 to a best of 100 . In all items a score of zero is given if the patient fails to provide an answer or responds inappropriately. Instructions may be repeated for each item, so as to elicit the patient's best possible performance. The overall time required to administer MODA ranges from 30 minutes in healthy controls to 45 minutes in deteriorated patients. The subsequent analysis and adjustment of scores takes minutes.

Mini mental state examination (MMSE).

One hundred and ninety healthy subjects of the whole sample were also given the MMSE, ${ }^{16}$ which yields a score from 0 to 30 . The missing data for 27 subjects are not from any systematic bias: they are simply the result of some organisational problems.

Table 1 Distribution according to age, education, and sex of the control subjects included in the study $(n=217)$

\begin{tabular}{|c|c|c|c|c|c|c|c|c|c|c|c|}
\hline \multirow[b]{2}{*}{ Sex } & \multirow[b]{2}{*}{ Education } & \multicolumn{10}{|l|}{ Age } \\
\hline & & $20-34$ & $35-44$ & $45-54$ & $55-59$ & $60-64$ & $65-69$ & $70-74$ & $75-79$ & $80-84$ & $\geqslant 85$ \\
\hline Women $(n=114)$ & $\leqslant 8$ years $(n=73)$ & 7 & 6 & 7 & 7 & 7 & 6 & 9 & 7 & 9 & 8 \\
\hline & $>8$ years $(n=41)$ & 6 & 3 & 4 & 3 & 6 & 4 & 6 & 3 & 3 & 3 \\
\hline $\operatorname{Men}(n=103)$ & $\leqslant 8$ years $(n=64)$ & 7 & 7 & 8 & 7 & 7 & 7 & 5 & 5 & 7 & 4 \\
\hline & $>8$ years $(n=39)$ & 6 & 6 & 2 & 5 & 3 & 8 & 2 & 4 & 2 & 1 \\
\hline Total $(n=217)$ & & 26 & 22 & 21 & 22 & 23 & 25 & 24 & 19 & 21 & 16 \\
\hline
\end{tabular}


Table 2 Means (SD) of the MODA total scores in the different age groups

\begin{tabular}{llllll}
\hline Age & No & Total score & Orientation & Autonomy & Tests \\
\hline $20-29$ & 21 & $97 \cdot 5(2 \cdot 7)$ & $35 \cdot 0(0 \cdot 0)$ & $15 \cdot 0(0 \cdot 0)$ & $47 \cdot 5(2 \cdot 7)$ \\
$30-39$ & 16 & $96 \cdot 6(2 \cdot 3)$ & $34 \cdot 9(0 \cdot 3)$ & $15 \cdot 0(0 \cdot 0)$ & $46 \cdot 7(2 \cdot 2)$ \\
$40-49$ & 19 & $95 \cdot 7(3 \cdot 1)$ & $34 \cdot 8(0 \cdot 7)$ & $15 \cdot 0(0 \cdot 0)$ & $45 \cdot 9(2 \cdot 7)$ \\
$50-59$ & 35 & $95 \cdot 1(3 \cdot 7)$ & $34 \cdot 9(0 \cdot 2)$ & $15 \cdot 0(0 \cdot 0)$ & $45 \cdot 2(3 \cdot 7)$ \\
$60-69$ & 48 & $94 \cdot 1(3 \cdot 8)$ & $34 \cdot 8(0 \cdot 4)$ & $14 \cdot 9(0.3)$ & $44 \cdot 2(3 \cdot 9)$ \\
$70-79$ & 41 & $92 \cdot 8(4 \cdot 5)$ & $34 \cdot 9(0 \cdot 2)$ & $14 \cdot 8(0 \cdot 6)$ & $43 \cdot 0(4 \cdot 4)$ \\
$80-85$ & 21 & $88 \cdot 9(7 \cdot 2)$ & $34 \cdot 6(0 \cdot 8)$ & $14 \cdot 8(0 \cdot 6)$ & $39 \cdot 6(6 \cdot 8)$ \\
$>85$ & 16 & $87 \cdot 4(7 \cdot 7)$ & $33 \cdot 7(2 \cdot 9)$ & $15 \cdot 0(0 \cdot 0)$ & $38 \cdot 6(5 \cdot 6)$ \\
Total & 217 & $93 \cdot 7(5 \cdot 2)$ & $34 \cdot 8(0 \cdot 8)$ & $14 \cdot 9(0 \cdot 3)$ & $43 \cdot 9(4 \cdot 9)$ \\
\hline
\end{tabular}

\section{Results}

Instructions were easily understood by all subjects. Tetrachoric correlation coefficients ${ }^{17}$ were calculated between the MODA subsections, due to the high incidence of top scores. Test subsection scores were split according to the median value, whereas the criterion used to dichotomise autonomy and orientation was maximum $v$ non-maximum scores. Computations were calculated with the Prelis programme. ${ }^{18}$ Correlation coefficients were 0.42 between orientation and autonomy, 0.47 between orientation and tests, and 0.47 between autonomy and tests. An analysis showed that these coefficients were all different from zero $(p<0.001)$.

Table 2 reports the means of the MODA scores according to age.

In the normal sample, the total variance of MODA was accounted for almost entirely by performance on the test section.

The MODA total score was submitted to multiple regression analysis to study the effect of age, education, and sex. The effects of the concomitant variables were first assessed individually and then studied within a simultaneous regression model to partial out their overlap. Effects were included in the final model only if they were still significant after this adjustment. Age and education were

Table 3 Linear regression models

\begin{tabular}{ll}
\hline Test & $\begin{array}{l}\text { Independent variables: } \\
\text { transformations, and } \\
\text { statistical significance }\end{array}$ \\
\hline MODA (Overall) & $\mathrm{F}(1,214)=62.969, \mathrm{p}<0.0001$ \\
Age: $\log (100-$ age) & $\mathrm{F}(1,214)=139.366, \mathrm{p}<0.0001$ \\
Education: square root & $\mathrm{F}(1,215)<1, \mathrm{NS}$
\end{tabular}

Final model: $93.72+3.64[\log (100-$ age $)-3 \cdot 53]+3.33(\sqrt{\text { education }}-2 \cdot 91)$

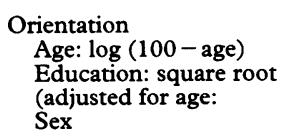

$\mathrm{F}(1,215)=32 \cdot 178, \mathrm{p}<0.0001$

$\mathrm{F}(1,215)=7 \cdot 305, \mathrm{p}=0.007$

$\mathrm{F}(1,214)=1.505, \mathrm{NS}$
$\mathrm{F}(1,215)<1, \mathrm{NS}$

Final model: $34 \cdot 80+0 \cdot 53[\log (100-$ age $)-3 \cdot 53]$

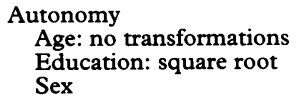

$\mathrm{F}(1,215)=5.932, \mathrm{p}=0.016$
$\mathrm{~F}(1,215)=2.742, \mathrm{NS}$

$\mathrm{F}(1,215)<1, \mathrm{NS}$

Final model: 14.93-0.003 (age-60.82)

Tests

Age: $\log (100-$ age $)$

Education: square roo

Sex
$\mathrm{F}(1,214)=50.203, \mathrm{p}<0.0001$

$\mathrm{F}(1,214)=124.011, \mathrm{p}<0.000$ $F(1,215)=<1$, NS
Final model: $43.95+3.03[\log (100-$ age $)-3.53]+3.29(\sqrt{\text { education }}-2.91)$

The degrees of freedom $(1,215)$ apply to the unadjusted test scores; the values $(1,214)$ are appropriate when the other variable has been partialled out.
Region where no

controlled judgement is possible

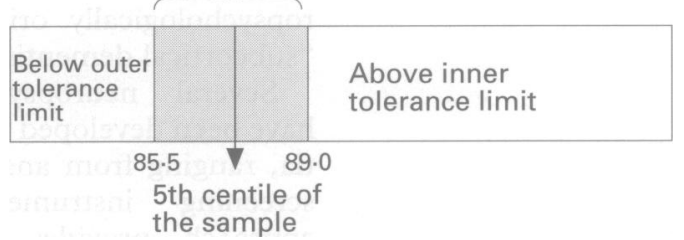

Scheme for the interpretation of the inner and outer tolerance limits. A performance above 89.0 is considered above the chosen threshold for normality. A score lower than $85 \cdot 5$ indicates a performance below the chosen cut off for normality. Age and education adjusted score between 85.5 and 89.0 cannot be unequivocally judged as being above or below the normality threshold.

included in the regression equation after mathematical transformations that explained a greater percentage of the test variance with respect to the original ones. Table 3 reports the linear models of the experimental variables and the adopted transformations, with the significance levels. For the model of the MODA subsections, age and education were significant for the test section, and age was significant for the orientation scale. No correction of the autonomy scale was required.

Table 3 also reports the statistical analysis of the influence of age, education, and sex on the MODA scores. Age was significant and likewise education, whereas sex did not play a significant part.

The model of the MODA total score provides a means of adjusting the raw scores according to age and education; this adjustment can be made by reversing the signs of the regression coefficients. ${ }^{19}$ On the adjusted scores we calculated the inner and the outer tolerance limits for the best $95 \%$ of the population, with $95 \%$ confidence. $^{20}$ If a subject scores between the inner and outer tolerance limits, no unequivocal assignment is possible, and the subject is more appropriately labelled

Table 4 Correction grid and tolerance limits of $M O D A$ total score. The correction values have to be added to or subtracted from each patient's raw score. No correction should be applied to a raw score of 100 (the maximum)

\begin{tabular}{|c|c|c|c|c|c|}
\hline \multirow[b]{2}{*}{ Age } & \multicolumn{5}{|c|}{ Education (y) } \\
\hline & 3 & 5 & 8 & 13 & 17 \\
\hline $\begin{array}{l}25 \\
30 \\
35 \\
40 \\
45 \\
50 \\
55 \\
60 \\
65 \\
70 \\
75 \\
80 \\
85\end{array}$ & $\begin{array}{l}1 \cdot 1 \\
1.3 \\
1.6 \\
1.9 \\
2 \cdot 2 \\
2.5 \\
2.9 \\
3.4 \\
3.9 \\
4 \cdot 4 \\
5.1 \\
5.9 \\
6.9\end{array}$ & $\begin{array}{c}-0.6 \\
-0.3 \\
0 \\
0.2 \\
0.5 \\
0.9 \\
1.3 \\
1.7 \\
2.2 \\
2.7 \\
3.4 \\
4.2 \\
5.3\end{array}$ & $\begin{array}{r}-2.6 \\
-2.3 \\
-2.0 \\
-1.7 \\
-1.4 \\
-1.1 \\
-0.7 \\
-0.3 \\
0.2 \\
0.8 \\
1.4 \\
2.2 \\
3.3\end{array}$ & $\begin{array}{r}-5.1 \\
-4.9 \\
-4.6 \\
-4.3 \\
-4.0 \\
-3.7 \\
-3.3 \\
-2.9 \\
-2.4 \\
-1.8 \\
-1.1 \\
-0.3 \\
0.7\end{array}$ & $\begin{array}{l}-6.9 \\
-6.6 \\
-6.3 \\
-6.0 \\
-5 \cdot 7 \\
-5.4 \\
-5.0 \\
-4 \cdot 6 \\
-4 \cdot 1 \\
-3.5 \\
-2.9 \\
-2.1 \\
-1.0\end{array}$ \\
\hline
\end{tabular}

Exact adjustment can be calculated from the formula: adjusted score $=$ original score $-3.64[\log (100-$ age $)-3.53]$ -3.33 ( education -2.91 ) One sided tolerance limits for the upper $95 \%$ of the population (adjusted scores) with $95 \%$ confidence: outer region $=<85.5$; inner region $=>89.0$; "uncertain" $=85 \cdot 5$ to $89 \cdot 0$. 
Table 5 Mean (SD) age and years of education of the sample in the validation study

\begin{tabular}{lccll}
\hline Groups & No & Sex $(M / F)$ & Age & Education \\
\hline Non-demented & 138 & $72 / 66$ & $60 \cdot 7(14 \cdot 6)$ & $7 \cdot 7(4 \cdot 2)$ \\
Demented: & 174 & $67 / 107$ & $68 \cdot 0(10 \cdot 6)$ & $7 \cdot 1(4 \cdot 3)$ \\
$\quad$ Probable Alzheimer's disease & 121 & $39 / 82$ & $68 \cdot 8(9 \cdot 2)$ & $6 \cdot 7(4 \cdot 1)$ \\
Other dementias & 53 & $28 / 25$ & $66 \cdot 3(13 \cdot 0)$ & $7 \cdot 9(4 \cdot 5)$ \\
Overall & 312 & $139 / 173$ & $64 \cdot 8(13 \cdot 0)$ & $7 \cdot 3(4 \cdot 2)$ \\
\hline
\end{tabular}

as a "borderline" case. The outer limits indicate the score under which there should be at most $5 \%$ of the normal population, and curb the risk of spuriously declaring that a subject is not normal. The inner limits indicate the score above which there should be at most $95 \%$ of the normal population, and are useful for curbing the risk of spuriously declaring a subject to be normal. For the MODA total score, the inner tolerance limit was 89.0 and the outer tolerance limit was $85 \cdot 5$ (see figure).

The inner and outer tolerance limits (tolerance regions) for the subscales of the MODA were respectively 34.3 and 33.8 for the orientation scale, 15.0 and 14.1 for the autonomy scale, and 38.8 and 36.2 for the tests section.

Table 4 presents a correction grid for the adjustment of the total raw scores of MODA according to age and education. The correction values, which are reported only for some combinations of age and education, have to be added to or subtracted from the raw score of each patient. Exact adjustments for intermediate values may be calculated directly from the formula reported in table 4 .

The reliability of the MODA was assessed by retesting 32 subjects (by a different examiner) after three weeks. The correlation between the performance in the two testing sessions was $0.83(\mathrm{df}=30, \mathrm{p}<0.001)$. On this basis, it was estimated that the $90 \%$ confidence limits for the true value of the single unadjusted score $^{21}$ were $\pm 2 \cdot 4$, and that the $95 \%$ confidence limits were $\pm 2 \cdot 9$.

The MMSE mean (SD) score was 28.45 $(2 \cdot 02)$, range $16-30$. The correlation between the MMSE and the MODA was 0.61 (df = $188, \mathrm{p}<0.001$ ).

\section{Discussion}

The MODA was modelled on the cognitive picture of Alzheimer's disease. ${ }^{11}$ Therefore it assesses so called cortical deficits, and is of value in ascertaining whether the cognitive performance of a subject is below the norm. Even so, it cannot be regarded as a comprehensive instrument for the diagnosis of dementia.

Table 6 MODA total and section scores of the 312 patients studied in our outpatient dementia units, classified according to the DSM-III-R.

\begin{tabular}{lllll}
\hline & $M O D A$ & Autonomy & Orientation & Tests \\
\hline Non-demented: $(\mathrm{n}=138)$ & $\mathbf{8 7 . 3 ( 8 \cdot 3 )}$ & $14 \cdot 2(1 \cdot 4)$ & $33 \cdot 3(2 \cdot 9)$ & $39 \cdot 8(6 \cdot 0)$ \\
Alzheimer's disease $(\mathrm{n}=121)$ & $51 \cdot 1(19 \cdot 4)$ & $13 \cdot 2(2 \cdot 0)$ & $19 \cdot 9(8 \cdot 3)$ & $18 \cdot 0(11 \cdot 1)$ \\
Other dementias: $(\mathrm{n}=53)$ & $69.5(18 \cdot 2)$ & $13.0(2 \cdot 4)$ & $27 \cdot 9(7 \cdot 3)$ & $28 \cdot 6(11 \cdot 4)$ \\
\hline
\end{tabular}

Results are mean (SD).
The MODA proved to be sensitive to age and education. With few exceptions, ${ }^{223}$ screening tests and rating scales that use hard cut offs disregard influential variables such as age and education and result in a many false positives. $^{2425}$ The statistical analysis of the MODA circumvents the risk of considering a subject not normal simply because he or she is old or poorly educated. This is of particular relevance given that several recent studies have reported a higher risk of dementia in those with lower educational levels. ${ }^{26-28}$

The correlation between the MODA total score and the MMSE was significant, but not high enough to support the view that these tests share the same structure.

Given the great variability in the neuropsychological profile of patients affected by Alzheimer's disease, ${ }^{29}{ }^{30}$ the MODA, which assesses independent areas of cognition, should add sensitivity to the dementing process. Furthermore, granted the different rates of progression of the disease ${ }^{31-33}$ the particular composition of the MODA should prove useful for longitudinal studies or pharmacological investigations. ${ }^{34} \mathrm{~A}$ validation study (part 2) was performed with the aim of verifying these predictions.

\section{Part 2: validation study}

\section{Materials and methods}

The testing material is as reported in part 1 .

\section{EXPERIMENTAL SUBJECTS}

Three hundred and twelve patients were referred to the Dementia Research Units of the University of Milan or the Medical centre of Veruno, with suspected dementia, first signalled by relatives and not immediately ruled out by a physician (usually a general practitioner). Table 5 shows features of the patient groups.

Two clinicians, who, although aware of the purpose of the study, had not been given the MODA score achieved by each patient, attempted a diagnosis of dementia on the basis of the dementia criteria of the DSM-IIIR. ${ }^{7}$ Cognitive deterioration was ruled out in 138 of the 312 subjects. Of the remaining $174,121(38.8 \%$ of the whole sample, and $69.5 \%$ of the demented patients) were given a diagnosis of probable Alzheimer's disease according to the formal criteria of the NINCDS-ADRDA. ${ }^{35}$ A further 53 patients were deemed to be affected by different forms of dementia.

\section{Results}

Tables 6 and 7 report the MODA findings for the sample of outpatients with suspected dementia compared with the outcome of the DSM-III-R classification.

On the whole, more patients were classified by the MODA as being affected by cognitive deterioration than by the DSM-III-R as demented, as in the same sample the MODA rated $71(22 \cdot 8 \%)$ as normal, $v 138(44 \cdot 2 \%)$ 
Table 7 Diagnostic categorisation of the neurogeriatric sample $(n=312)$ according to

\begin{tabular}{lccr}
\hline & MODA & & \\
\cline { 2 - 4 } & Normal & Uncertain & Not normal \\
\hline $\begin{array}{l}\text { DSM-III-R: } \\
\begin{array}{l}\text { Non-demented } \\
\text { (n= 138) }\end{array}\end{array}$ & $67(48 \cdot 5)$ & $28(20 \cdot 3)$ & $43(31 \cdot 2)$ \\
$\begin{array}{l}\text { Demented: Alzheimer's disease } \\
\text { (n=121) }\end{array}$ & $0(0)$ & $3(2 \cdot 5)$ & $118(97 \cdot 5)$ \\
$\begin{array}{l}\text { Demented: non-Alzheimer's disease } \\
(\mathrm{n}=53)\end{array}$ & $4(7 \cdot 5)$ & $8(15 \cdot 1)$ & $41(77 \cdot 4)$ \\
\hline
\end{tabular}

Results are number (\%). the DSM-III-R and the MODA

MODA was 1.06 (SD 1.25 ), range -0.06 to 5.44. This should be useful for gauging the effect of treatments in clinical trials. On an annual basis, 28 patients out of 35 worsened to an extent greater than the confidence limits of the score (2.9 points). Average worsening on the autonomy scale is less informative, as its course is likely to be non-linear. Interestingly, the mean estimated duration of illness of the 42 patients with Alzheimer's disease with pathological scores on both the test and orientation sections, but not on autonomy, was 3.12 (SD 2.51) years, whereas that of the 67 patients with all three sections below the norm was 4.33 (SD 3.31) years. This difference was significant $(t=2 \cdot 03, \mathrm{p}=0 \cdot 04)$.

Thirty one patients with Alzheimer's disease were given both the MODA and the MMSE. The correlation coefficient with the MMSE was $0.84(p<0.001)$. were definitely outside the norm with the MODA were considered normal according to the DSM-III-R, whereas only four showed the opposite pattern. Table 8 gives details of the 43 subjects.

Thirty five of the 121 patients with probable Alzheimer's disease were retested with the MODA after a mean interval of 15.3 months. These patients were less severely affected than those who could not be re-examined (mean MODA score $=66.2$ (SD 18), $v 44.9$ (SD $19 \cdot 2$ ), but were of similar age and education. This selection is presumably due to the fact that the compliance of patients who were most severe at the first examination decreased with the disease progression. We think that this selection does not, however, make following up patients with moderately severe Alzheimer's disease any less interesting. Table 9 shows the results.

The MODA is well suited to monitoring the disease progression. The average monthly deterioration of patients' performance on the

Table 8 Subjects judged non-demented by the DSM-III-R $(n=43)$ who scored below the norm on the sections of the MODA (autonomy, orientation, and tests)

\begin{tabular}{ll}
\hline & No of subjects \\
\hline Subjects outside the norm on: & 2 \\
$\quad$ Autonomy only & 9 \\
Orientation only & 9 \\
Tests only & 3 \\
Orientation and autonomy & 7 \\
Orientation and tests & 6 \\
Tests and autonomy & 7 \\
All sections: & \\
Overall: & 18 \\
$\quad$ Autonomy & 26 \\
Orientation & 29 \\
Tests & \\
\hline
\end{tabular}

Table 9 MODA follow up of 35 patients with Alzheimer's disease who underwent a second testing session (mean interval 15.5 months)

\begin{tabular}{|c|c|c|c|c|}
\hline & $\begin{array}{l}\text { MODA } \\
\text { overall }\end{array}$ & Autonomy & Orientation & Tests \\
\hline $\begin{array}{l}\text { First examination } \\
\text { Second examination } \\
\text { Student's } t \text { value } \\
\text { p Value }(\mathrm{df}=34)\end{array}$ & $\begin{array}{l}66 \cdot 1 \\
49 \cdot 6 \\
5 \cdot 847 \\
<0 \cdot 0001\end{array}$ & $\begin{array}{l}14 \cdot 6 \\
12 \cdot 8 \\
5 \cdot 054 \\
<0.0001\end{array}$ & $\begin{array}{l}26 \cdot 1 \\
20 \cdot 1 \\
4 \cdot 979 \\
<0 \cdot 0001\end{array}$ & $\begin{array}{l}25 \cdot 4 \\
16 \cdot 7 \\
5 \cdot 367 \\
<0 \cdot 0001\end{array}$ \\
\hline Average monthly deterioration & 1.059 & $0 \cdot 114$ & $0 \cdot 385$ & 0.560 \\
\hline
\end{tabular}

\section{Discussion}

The MODA meets the requirements for a ment, ${ }^{2}$ given that a large group of unselected patients entered the validity study and a standardised diagnostic procedure was employed.

As shown in table 7 , only four of the patients who were classified as demented (although not of the Alzheimer's type) by the DSM III-R achieved a normal MODA score. Conversely, $31 \cdot 2 \%$ of the subjects who were not demented according to the DSM-III-R scored below the MODA chosen cut off (and $20.3 \%$ were classed as uncertain).

This MODA/DSM-III-R inconsistency possibly stems from the greater sensitivity to cognitive decline of neuropsychological items than of general behavioural issues. This is not to be read as a fault of the DSM-III, but rather it points to a lack of overlapping between the different nosographic categories considered by the two instruments. The MODA in fact, is designed to detect and score cognitive deterioration, whereas the DSM-III is thought of as a clinical tool guiding the diagnosis of dementia.

The opposite pattern, patients who were normal on the MODA and demented on the DSM-III-R, was seldom seen (only four cases out of $174(2 \cdot 3 \%))$. This discrepancy may have arisen as a result of a defect in specificity of the DSM-III, the patients at issue could indeed be non-demented, or a lack of sensitivity of the MODA. In the last case, the MODA enquiry could have failed to detect a behavioural defect in non-Alzheimer's disease patients, with a poor neuropsychological counterpart (for example, heterogeneous psychiatric traits). Anyhow, this error rate seems acceptable.

In short the MODA seems to be a fairly sensitive screening instrument for dementia, and this may be of importance as all too often the screening tests used in dementia studies show a high rate of false negative classifications. ${ }^{2}$

This has been confirmed in a population study we recently carried out, with a view to reliable bedside cognitive screening instru- 
determining the prevalence of dementia. ${ }^{36}$ In that study we compared the outcome of MODA with that of the MMSE in serving as a "red flag" for further investigation of a sample of elderly subjects selected from the community. The two tests were given to 782 subjects. The correlation between the two measures was $0.67(p<0.001)$, similar to the one reported in the present study. Subjects with a score below the cut off on either of the two tests $(n=219)$ entered a standardised two stage diagnostic procedure that included clinical, neuropsychological, and when needed, neuroradiological investigation and a follow up period of at least one year, aimed at detecting cognitive problems. The results demonstrated a higher sensitivity $(95.5 \%$ v $67 \cdot 4 \%)$ and a higher specificity $(100 \% v 94 \cdot 1 \%)$ of the MODA compared with the MMSE in detecting subjects with cognitive deficits. The price of this higher sensitivity is of course a greater number of subjects to be considered in the follow up; however, this did not exceed $4 \%$ of the whole sample. Therefore, we are fairly confident in stating that MODA is more satisfactory than MMSE as a screening test.

\section{General discussion}

The need in both clinical practice and research for standardised instruments able to grade the cognitive ability of demented patients is undeniable. Nevertheless, a limitation inherent in many of the rating scales specifically designed to assess demented patients is that they are appropriate for only certain subgroups such as very severely or very mildly deteriorated patients. ${ }^{37}$ Instruments that disclose abnormalities only when the disease is manifest add little to the diagnosis and staging of the disease..$^{38}$ On the other hand, sophisticated neuropsychologically oriented instruments are of little use in the later stages of the disease. ${ }^{39}$

Recently Rebok and Folstein ${ }^{40}$ maintained that the development of "more sensitive and specific criteria for the diagnosis are needed". Their contention was directed towards the forthcoming revision of DSM-III-R (DSMIV). We could not agree more. Our approach to this widely felt need has been different, however, in as much as we deem that improving the diagnostic keenness is likely to be linked to a psychometric fine grained elaboration (for example, score adjustable for age and education) of a standardised instrument possibly framed in a clear cut theoretical commitment. In our view most of the phenomena shown by demented patients achieve a descriptive coherence in a neuropsychological context.

The MODA does not rule out the need for an accurate collection of the history, as only this gives the clinician the opportunity to formulate the suspicion of dementia and recommend psychometric assessment. The test cannot be used as a comprehensive instrument for the diagnosis of dementia. A normal MODA score, however, makes true dementia a very unlikely diagnosis.
Other instruments have been devised by checklisting neuropsychological items, such as the CAMCOG section in the CAMDEX. ${ }^{10}$ The guidelines of Roth et $a l^{10}$ do not, however, conceive dementia as a neuropsychological disease. Accordingly, Roth et al ${ }^{10}$ do not rely heavily on CAMCOG, to any great extent, to stage and diagnose dementia. The MODA is also a handier instrument and, unlike the CAMCOG, provides a means to adjust the scores for age and education.

Each of the heterogeneous sets of tools designed for the "global" assessment of mental state has proved to be highly sensitive to cognitive impairment, despite vast differences in composition and theoretical background. Thus it is tempting to suggest that the crucial contribution to the resulting score is fairly content free. Such a state of affairs would be disappointing. Given that the genuine neuropsychological requirements are those that substantially enhance the sensitivity of the instruments that include them, we believe that the overall sensitivity of the many tools proposed stems from their neuropsychological overlaps. A neuropsychologically oriented staging instrument such as MODA is a further step towards generating instruments within a cognitive frame of reference. Turning now to severity one might refer to an all encompassing cognitive defect (a Grundstörung) and range severity accordingly. On the other hand, it could be suggested that the behavioural incompetence seen in demented people derives from several assembled deficits in conceptually independent cognitive realms. We favour this second view, hence the MODA score is merely the sum of graded impairments in a large array of cognitive domains. The accuracy of a global score in describing the severity of dementia would therefore be achieved notwithstanding the heterogeneous pattern of the disease. ${ }^{29}$ Therefore, we maintain that the MODA is a successful compromise between comprehensive, but impractical neuropsychological test batteries and bedside instruments that fail to tap important aspects of cortical dementias.

We are grateful to Colin Grey who has taken time to discuss with us the results reported in this article, and to Gilian Jarvis who revised the English. The research was partly supported by a grant to HS of the Consiglio Nazionale delle Ricerche N:CT 87.00233.04.115.12235). Authors are listed in alphabetical order, and this does not imply differential contribution to the paper.

Preliminary data were presented at the Meeting of the European Federation of Neurological Societies (EFNS). European Federation of $\mathrm{Neur}$

\section{Appendix}

AUTONOMY SCALE

This scale measures everyday coping skills and is the only non-neuropsychological section of the MODA. As it is predicted that performance on this section will be hampered only in the later stages of the dementia, it should enable us to score even the most deteriorated patients. The examiner needs the collaboration of someone who is able to provide information about the subject's present behaviour. The section considers five aspects 
of everyday living: walking, dressing, personal hygiene, control of sphincters, and eating. The score for each question ranges from 0 (in need of total supervision) to 3 (total autonomy). Answers are sought from a close relative. The overall score range is $0-15$.

\section{ORIENTATION ENQUIRY}

This section is made up of four different sets of items. The items require the subject to produce information that either changes (for example, age) or remains the same (for example, date of birth) over time. An answer is accepted when checked against the "truth" (documents or witnesses). The score range of the entire section is $0-35$. The four sets of items are:

Temporal orientation-Five question are asked: the day of the week, the date of the month, the month, the year, and the time of day, following the procedure of Benton et al. ${ }^{41}$ The score ranges from 0 to 10 .

Spatial orientation ${ }^{42}$-Three questions requiring topographical information on town and country are asked. The score ranges from 0 to 3 .

Personal orientation ${ }^{42}$-Seven questions regarding personal background are asked. Standardised items are weighted differently according to face value difficulty. The score ranges from 0 to 10 .

Family orientation ${ }^{42}$ - The subject is asked the name and age ( \pm 5 years) of four different family members, and whether they are alive or dead. The score ranges from 0 to 12 .

\section{NEUROPSYCHOLOGICAL TESTS}

All tests are drawn from an Italian standardised series $^{43}$ of formal, currently employed, neuropsychological tests. Only the easiest items have been chosen to avoid, as far as possible, a "floor performance" in demented patients. The score range for the whole section is $0-50$.

Tests assess attention (digit cancellation; reversal learning), intelligence (logical reasoning), memory (prose memory), language (verbal comprehension; fluency), space cognition (finger agnosia; constructional apraxia), and visual perception (figure completion). They are detailed here in the order of administration:

\begin{tabular}{|c|c|c|}
\hline Test & No of items & Score range \\
\hline Reversal learning ${ }^{44}$ & 5 & $0-5$ \\
\hline Digit cancellation test ${ }^{45}$ & 10 & $0-10$ \\
\hline Logical reasoning ${ }^{43}$ & & $0-6^{\star}$ \\
\hline Prose memory ${ }^{33}$ & 16 units & $0-8$ \\
\hline Semantic word fluency ${ }^{46}$ & & \\
\hline (names of animals) & & $0-5 \dagger$ \\
\hline Token test ${ }^{47}$ & 5 & $0-5$ \\
\hline Finger agnosia ${ }^{48}$ & 5 & $0-5$ \\
\hline Construction apraxia ${ }^{49}$ & 3 & $0-3$ \\
\hline Street completion test ${ }^{50}$ & 3 & $0-3$ \\
\hline
\end{tabular}

* Subjects are requested to say what is different between a truck and a coach and the meaning of a well known proverb. truck and a coach and the meaning of a

tScore is categorised according to the number of words produced in two minutes and weighted against norms. ${ }^{43}$

1 Wells CE. Dementia. Philadelphia: FA Davis Co, 1977

2 Nelson A, Fogel BS, Faust D. Beside cognitive screeni instruments. A critical assessment. $\mathcal{f}$ Nerv Ment Dis 1986;174:73-83.
3 Spinnler H, Della Sala S. The role of clinical neuropsychology in the neurological diagnosis of Alzheimer's disease. $¥$ Neurol 1988;235:258-71.

4 Kokmen E, Smith GE, Petersen RC, Tangalos E, Ivnik RC. The short test of mental status. Correlation with standardized psychometric testing. Arch Neurol 1991; 48:725-8.

5 Wilcock JK, Hope RA, Oppenheimer C, Reynolds JP, Rossor MN, Davies MB. Recommended minimum data to be collected in research studies on Alzheimer's disease. I Neurol Neurosurg Psychiatry 1989;52: 693-700.

6 Riege WH, Metter EJ. Cognitive and brain imaging measures of Alzheimer's disease. Neurobiol Aging 1988; 9:69-86

7 American Psychiatric Association. Diagnosis and statistical manual of mental disorders, revised third edition. Washington, DC: American Psychiatric Association, 1987.

8 Chang Chui H. Dementia. A review emphasizing clinicopathologic correlation and brain-behavior relationships. Arch Neurol 1989;46:806-14.

9 Welsh KA, Butters N, Hughes JP, Mohs RC, Heyman A. Detection and staging of dementia in Alzheimer's disDetection and staging of dementia in Alzheimer's dis-
ease. Use of the neuropsychological measures developed for the consortium to establish a registry for Alzheimer's disease. Arch Neurol 1992;49:448-52.

10 Roth M, Tym E, Mountioy CQ et al. CAMDEX: a standardized instrument for the diagnosis of mental disorder in the elderly with special reference to the early detection of dementia. Br f Psychiatry 1986;149:698-709.

11 Nebes RD. Cognitive dysfunction in Alzheimer's disease. In: Craik FIM, Salthouse TA, eds. The handbook of aging and cognition. Hillsdale: LEA, 1992:373-446.

12 Strub RL, Black WF. The mental status examination in neurology. Philadelphia: FA Davis, 1987.

13 Hughes CP, Berg L, Danzinger WL, Coben LA, Martin RL. A new clinical scale for the staging of dementia. $B r f$ Psychiatry 1982;140:566-72.

14 Lau C, Wands K, Merskey H, Boniferro M, Carriere L, Fox H, Hachinski VC. Sensitivity and specificity of the extended scale for dementia. Arch Neurol 1988;45: 849-52.

15 Jorm AF. The epidemiology of Alzheimer's disease and related disorders. London: Chapman and Hall, 1990

16 Folstein MF, Folstein SE, McHugh PR. "Mini mental state": a practical method for grading the cognitive state of patients for the clinician. $\mathcal{F}$ Psychiatr Res 1975;12: 189-98.

17 McNemar Q. Psychological statistics. New York: J Wiley, 1962.

18 Joereskog KG, Soerbom D. Prelis. 2nd ed. Mooresville, IN: Scientific Software Inc, 1988.

19 Capitani E, Laiacona, M. Aging and psychometric diagnosis of intellectual impairment: Some considerations on test scores and their use. Developmental Neuropsychology test scores and

20 Ackermann H. Mehrdimensionale nichtparametrische Normbereiche. Berlin: Springer, 1985.

21 Gulliksen H. Theory of mental tests. Hillsdale: LEA, 1987.

22 Bleecker ML, Bolla-Wilson K, Kawas C, Agnew J. Agespecific norms for the Mini Mental State Examination. Neurology 1988;38:1565-8.

23 Measso G, Cavarzeran F, Zappalà G, et al. The MiniMental State Examination: normative study of an Italian random sample. Developmental Neuropsychology 1993;9: 77-85.

24 Anthony JC, Le Resche L, Niaz U, Von Korff MR, Folstein MF. Limits of the "Mini-Mental State" as a screening test for dementia and delirium among hospital patients. Psychol Med 1982;12:397-408.

25 Faust D, Fogel BS. The development and initial validation of a sensitive bedside cognitive screening test. $\mathcal{F}$ Nerv Ment Dis 1989;177:25-31.

26 Friedland RP. Epidemiology, education, and the ecology of Alzheimer's disease. Neurology 1993;43:246-9.

27 Katzman R. Education and the prevalence of dementia and Alzheimer's disease. Neurology 1993;43:13-20.

28 Hiil LR, Klauber MR, Salmon DP, et al. Functional status, education, and the diagnosis of dementia in the Shangai survey. Neurology 1993;43:138-45.

29 Capitani E, Della Sala S, Spinner H. Neuropsychological approach to dementia. In: Poeck $\mathrm{K}$, Freund HJ, Gaenshirt H, eds. Neurology. Berlin: Springer-Verlag, 1986:61-9.

30 Martin A, Brouwers P, Lalonde F, Cox C, Teleska P, Fedio P. Towards a behavioral typology of Alzheimer's patients. F Clin Exp Neuropsychol 1986;8:594-610.

31 Katzman R, Brown T, Thal LJ. Comparison of rate of annual change of mental status score in four independent studies of patients with Alzheimer's disease. Ann Neurol 1988;24:384-9.

32 Burns A, Jacoby R, Levy R. Progression of cognitive impairment in Alzheimer's disease. $\mathcal{F}$ Am Geriatr Soc 1991;39:39-45.

33 Lucca U, Comelli $M$, Tettamanti $M$, Tiraboschi $P$, Spagnoli A. Rate of progression and prognostic factors in Alzheimer's disease: a prospective study. $\mathcal{F} \mathrm{Am}$ Geriatr Soc 1993;41:45-9.

34 Zec RF, Landreth ES, Vicari SK, Belman J, Feldman E, Andrise A, Robbs R, Becker R, Kumar V. Alzheimer disease assessment scale: a subtest analysis. Alzheimer Dis Assoc Disord 1992;6:164-81.

35 McKhann G, Drachman D, Folstein M, Katzman R, Price D, Stadlan EM. Clinical diagnosis of Alzheimer's 
disease: report of the NINCDS-ADRDA Work Group under the auspices of Department of Health and Human Services Task Force on Alzheimer's Disease. Neurology 1984;34:939-44.

36 Della Sala S, Musicco M, Spinnler H, Ubezio MC. MODA (Milan Overall Dementia Assessment); no strumento utile per la valutazione di normalita cognitiva negli studi di popolazione. In Cosi V, Citterio A eds. Invecchiamento cerebrale. Problemi metodologici negli studi di popolazione. Pavia: Il Grifone, 1993:7-22 (In

37 Salzman C, Kochansky GE, Shader R. Rating scales for geriatric psychopharmacology-a review. Psychopharmacol Bull 1972;8:3-50.

38 Galasko D, Klauber MR, Hofstetter CR, Salmon DP, Lasker B, Thal LJ. The Mini Mental State Examination in the early diagnosis of Alzheimer's disease. Arch Neurol 1990;47:49-52.

39 Rosen WG, Mohs RC, Davis KL. A new rating scale for Alzheimer's disease. Am f Psychiatry 1984;141:1356-64.

40 Rebok GW, Folstein MF. Dementia. I Neuropsychiatry Clin Neurosci 1983;3:265-76.

41 Benton AL, Van Allen MW, Fogel ML. Temporal orientation in cerebral disease. If Nerv Ment Dis 1964; tion in ceret

42 Della Sala S, Spinnler H. "Indifference amnesique" in a case of global amnesia following acute brain hypoxia. Eur Neurol 1986;25:98-109.

43 Spinnler H, Tognoni G. (eds.) Taratura e Standardizzazione Italiana di Test Neuropsicologici. Ital $\mathcal{f}$ Neurol Sci 1987;6(suppl 8):12-120.

44 Golden CJ. A standardized version of Luria's neuropsychological tests. In Filskov SB, Boll TJ, eds. Handbook of clinical neuropsychology. Chichester: Wiley, 1980.

45 Della Sala S, Laiacona M, Spinnler H, Ubezio MC. A cancellation test: its reliability in assessing attentiona deficits in Alzheimer's disease. Psychol Med 1992;22 $885-901$.

46 Della Sala S, Lorenzi L, Spinnler H, Zuffi M. Componen of the breakdown of verbal communication in Alzheimer's disease. Aphasiology 1993;7:285-300.

47 De Renzi E, Vignolo LA. The token test: a sensitive test to detect receptive disturbances in aphasia. Brain 1962;85: 665-78.

48 Benton AL, Hamsher $\mathrm{K}$ deS, Varney NR, Spreen $O$ Contributions to neuropsychological assessment. A clinical manual. New York: Oxford University Press, 1983.

49 Arrigoni C, De Renzi E. Constructional apraxia and hemispheric locus af lesion. Cortex 1964;1:170-97.

50 Street RF. A Gestalt completion test. Contribution to education. No 481. New York: Bureau of Publications. Teachers College, Columbia University, 1931. 